\title{
POLA PERBELANJAAN BELIA MELAYU B40 DAN M40 DI KUALA LUMPUR
}

\section{(The Pattern of Consumption of B40 and M40 Youth in Kuala Lumpur)}

Nur Jannah Bukhari*

jannabukhari@gmail.com

Marzudi Md Yunus

marzudi@um.edu.my

Jabatan Sosio-Budaya/ Kesenian Melayu, Akademi Pengajian Melayu, Universiti Malaya

Kim Keum Hyun

korea@um.edu.my

Jabatan Bahasa Asia dan Eropah, Fakulti Bahasa dan Linguistik, Universiti Malaya.

Aida Idris

aida_idris@um.edu.my

Jabatan Polisi dan Perancangan Perniagaan, Fakulti Perniagaan dan Perakaunan, Universiti Malaya.

Terbit dalam talian (published online): 1 Januari 2021

Sila rujuk: Nur Jannah Bukhari, Marzudi Md Yunus, Kim Keum Hyun dan Aida Idris. (2021). Pola Perbelanjaan Belia Melayu di Kuala Lumpur. Melayu: Jurnal Antarabangsa Dunia Melayu, 14(1), 45-68.

\begin{abstract}
Abstrak
Fokus kajian ini adalah untuk menganalisis perbelanjaan belia kumpulan B40 dan M40 yang menetap di bandar, iaitu Kuala Lumpur berdasarkan keperluan tertentu. Bagi mencapai objektif kajian ini, satu kerangka kajian tentang keperluan yang diutamakan ketika berbelanja telah dibangunkan. Keperluan tersebut merangkumi keperluan asas, perlindungan dan kesihatan, keluarga, agama, dan masa lapang.
\end{abstract}


Hasil dapatan kajian memperlihatkan bahawa tiada perbezaan yang signifikan antara kedua-dua kumpulan tersebut ketika berbelanja. Walau bagaimanapun, terdapat perbezaan keutamaan ketika berbelanja yang didorong oleh keinginan untuk menjamin kelangsungan hidup di bandar. Walaupun keperluan asas seperti pemilikan rumah sering menjadi topik perbincangan dalam kajian perbelanjaan khususnya bagi kumpulan berpendapatan rendah dan sederhana, harga rumah yang tidak mampu milik lebih-lebih lagi di bandar telah menyebabkan perbelanjaan bagi keperluan perumahan membeli rumah bukanlah penyumbang utama dalam keseluruhan perbelanjaan. Kajian ini mengetengahkan bahawa jenis penempatan menyumbang kepada bentuk gaya hidup dan perbelanjaan yang menjadi amalan oleh golongan belia di bandar.

Kata kunci: bandar, belia, keperluan, Melayu, pendapatan, perbelanjaan

\begin{abstract}
This study focuses on analyzing the spending patterns of youths from across the B40 and M40 income strata living in Kuala Lumpur. To achieve the objectives of this study, an analytical framework was developed that prioritizes needs. These needs include basic necessities, shelter and health, family, religious matters, and free time. The results of this study show that there is no significant difference between the two groups in terms of spending patterns. However, there is a difference in terms of priorities, which are led by the desire to guarantee survival in the city. Basic necessities, such as house ownership, feature as top topics in the discussion of expenditure, especially among lower and middle-income groups. However, the pricing of homes which renders them unattainable to these two groups, especially in the urban setting, results in expenses related to home purchases not being a main item in their spending patterns. This study highlights that the type of residence contributes to the shaping of the lifestyle and spending patterns of urban youth.
\end{abstract}

Keywords: urban, youth, needs, Malay, income, expenditure

\title{
PENDAHULUAN
}

Pola perbelanjaan merupakan antara perkara yang sering diberikan perhatian oleh pelbagai pihak, baik pihak kerajaan melalui jabatan penyelidikan yang dilantik, mahupun badan penyelidikan bebas. Hal ini demikian kerana pola perbelanjaan yang dilakukan secara tidak langsung memberikan impak kepada pendapatan negara. Namun demikian, terdapat pelbagai cabaran yang bakal dihadapi oleh pengguna ketika berbelanja. Cabaran tersebut akan lebih terkesan jika pengguna 
tersebut tergolong dalam kumpulan berpendapatan rendah. Pendapatan rendah mengurangkan kuasa membeli pengguna yang diakibatkan oleh faktor ekonomi dan harga barangan yang semakin meningkat. Keadaan ini menjadi bertambah sukar lebih-lebih lagi jika mereka menetap di kawasan bandar. Hal ini demikian kerana variasi demografi penduduk bandar merancakkan lagi permintaan bagi keperluan asas. Lambakan penawaran produk dan barangan yang cenderung memenuhi pelbagai latar belakang masyarakat berdasarkan identiti tertentu, mempengaruhi cita rasa pengguna ketika berbelanja. Sudah tentu, pengguna yang terdiri daripada kumpulan belia dalam kumpulan B40 dan M40 menjadi kumpulan yang paling terjejas.

Di bandar, terdapat sejumlah pendapatan yang sekurang-kurangnya perlu diperoleh oleh belia agar dapat menikmati kehidupan yang lebih sejahtera. Kumpulan Simpanan Wang Pekerja (KWSP) (2019) mengetengahkan panduan untuk menetap di sekitar Lembah Klang, golongan bujang tanpa kereta memerlukan sekurangkurangnya RM1,870, manakala yang berkereta, RM2,490. Bagi yang berkahwin tanpa anak pula memerlukan RM4,420 sementara yang mempunyai anak sehingga dua orang, RM5,370 hingga RM6,620. Pasangan warga emas pula memerlukan sekurang-kurang RM3,090

Berdasarkan hujah tersebut, dapat difahami bahawa tingkat pendapatan secara tidak langsung membentuk pola perbelanjaan yang tersendiri berdasarkan keutamaan yang berbeza-beza. Lebih-lebih lagi apabila menetap di bandar, warga bandar berdepan dengan cabaran dan kesukaran untuk menyeimbangkan keperluan yang pelbagai dengan pendapatan yang terhad. Dengan erti kata yang lain, keadaan ini sedikit sebanyak menyebabkan pecahan perbelanjaan sedia ada yang diamalkan oleh golongan B40 dan M40 perlu dirombak agar keperluan dalam pelbagai aspek dapat dipenuhi. Namun demikian, sejauh manakah perbezaan perbelanjaan antara golongan berpendapatan rendah dan sederhana yang menetap di bandar menjadi persoalan.

\section{SOROTAN KAJIAN}

Isu perbelanjaan dan hubungannya dengan pendapatan sering menjadi fokus pengkaji dalam bidang ekonomi dan kesejahteraan sosial. Kajian mengenai topik ini telah bermula sekitar akhir tahun 1950 oleh Duesenberry (1949) dengan pendekatan "Hipotesis Pendapatan Relatif" atau "Relative Income Hipotesis". Pengkaji ini telah membuat andaian bahawa ketika berbelanja, terdapat kecenderungan dalam kalangan masyarakat untuk bersaing sesama mereka. Pada masa yang sama, persaingan itu 
membantu mereka untuk berusaha dengan lebih keras bagi meningkatkan kualiti hidup. Oleh itu, apabila telah mencapai satu tahap kualiti hidup yang diingini, mereka tidak mahu menurunkan tahap kehidupan atau standard yang sedang dan telah dikecapi walaupun pada ketika itu pendapatan telahpun mulai menurun.

Namun begitu, Friedman (1957) dalam "Hipotesis Pendapatan Tetap" atau "The Permanent Income Hyphotesis" membawa pemahaman dari sisi yang berbeza dengan beranggapan bahawa perubahan dalam berbelanja tidak mudah untuk dijangka kerana jangkaan setiap individu adalah berbeza. Di samping itu, individu berbelanja secara konsisten dengan jangkaan purata pendapatan mereka dalam tempoh masa yang panjang. Tahap jangkaan pendapatan bagi tempoh masa yang panjang ini akhirnya menjadi tahap pendapatan "kekal" (level of permanent income) yang membolehkan pengguna berbelanja dengan baik dan selamat.

Ando dan Modigliani (1963) dalam "Hipotesis Penyimpanan Mengikut Kitaran Hidup" atau "The Life Cycle Hypothesis of Saving" pula telah membangunkan teori perbelanjaan berdasarkan pertimbangan bahawa wujud hubungan antara kitaran hidup (life-cycle), pendapatan, dan perbelanjaan bagi keperluan isi rumah. Pengkaji ini berpendapat, individu akan merancang perbelanjaan mereka bagi sepanjang hidup terlebih dahulu dengan mengandaikan jumlah pendapatan yang bakal diterima pada masa depan adalah sama.

Sekitar tinjauan terhadap kajian terdahulu yang telah dilaksanakan, terdapat beberapa aspek perbelanjaan dan pendapatan telah diberikan perhatian. Dalam isu golongan berpendapatan sederhana, The Edge (2019) menemukan, golongan berpendapatan pertengahan juga berdepan dengan permasalahan dari segi perbelanjaan, sama seperti golongan berpendapatan rendah. Rusli Latimaha et al. (2018) dalam kajiannya pula telah mengenal pasti faktor yang mempengaruhi perbelanjaan asas di tiga buah bandar utama yang mempunyai kos sara hidup yang tinggi di Malaysia, iaitu Kuala Lumpur, Pulau Pinang, dan Johor. Analisis kajian yang dilakukan mendapati terdapat perbezaan belanjawan keperluan asas antara isi rumah bujang dewasa di Kuala Lumpur dan Johor Bahru, dan antara isi rumah yang kedua-dua ibu bapa yang bekerja di tiga buah bandar utama.

Nurshuhada Zainon et al. (2017) pula menerusi kajian mengenai perbelanjaan terhadap keperluan asas, iaitu aspek perumahan, didapati bahawa kesukaran kumpulan pendapatan pertengahan di Lembah Klang untuk memiliki rumah bukanlah disebabkan oleh ketidakmampuan kewangan namun, disebabkan oleh situasi kewangan mereka yang di luar kelayakan. Isu ini dapat dikaitkan melalui dapatan Wan Nor Azriyati (2011) yang menemui kes seperti keengganan penyewa untuk keluar dari flat perumahan kos rendah (perumahan awam subsidi). Situasi 
ini mendedahkan, kesukaran untuk mendapatkan rumah pada harga mampu milik memaksa mereka untuk mengurangkan kos perbelanjaan bagi satu-satu keperluan agar keperluan yang lain dapat diseimbangkan.

Bagi kajian yang tertumpu pada golongan berpendapatan rendah pula, golongan B40 yang menetap di bandar merupakan golongan miskin bandar dan lazimnya, mereka akan membelanjakan sebahagian besar pendapatan bagi memenuhi barang keperluan asas dan utiliti (Bank Negara, 2015). Dengan erti kata yang lain, kumpulan berpendapatan rendah tidak mempunyai lebihan kewangan kerana jumlah perbelanjaan hampir setara dengan jumlah pendapatan yang diperoleh. Mereka terpaksa berdepan dengan tekanan dan kesan inflasi yang lebih tinggi berbanding dengan yang berpendapatan lebih tinggi. Agensi Kaunseling Pengurusan Kredit (AKPK) seperti yang dilaporkan oleh Sabstu, (2014) menjelaskan, permasalahan kos sara hidup yang melibatkan peningkatan harga barangan komoditi perlu ditangani. Jika tidak, kumpulan yang terlibat akan lebih tertekan dan akhirnya kesejahteraan seseorang individu dan isi rumah akan terjejas.

\section{JENIS KEPERLUAN MENURUT SARJANA}

Untuk menjamin kelangsungan hidup, terdapat keperluan tertentu yang perlu dipertimbangkan, sama ada perlu perhatian yang lebih tinggi atau sebaliknya. Keperluan tersebut juga berbeza antara satu sama lain antaranya seperti yang dinyatakan oleh Maslow (1943), Rosenberg (1960), Burton (1990), dan Max-Neef (1992).

Maslow (1943) dilihat sebagai pelopor yang telah membincangkan dimensi keperluan dalam kehidupan manusia. Menurutnya dalam "A Theory of Human Motivation", terdapat lima jenis keperluan yang diperlukan setiap manusia dan keperluan tersebut berbentuk hierarki. Dimulai dengan keperluan dasar, iaitu

fisiologi, keselamatan, kepunyaan, penghormatan, dan keinginan. Rosenberg (1960) kemudiannya dengan model "Non-violent Communication" membahagikan keperluan kepada tujuh, iaitu pemberian kasih dalam bentuk fizikal, kebergantungan kepada seseorang, kejujuran dan adil, hak atau kuasa atas sesuatu, bermain, perayaan atau berkabung, dan yang terakhir, kebersamaan dan semangat dalam satu kumpulan. Pengkaji ini menggunakan pendekatan bahawa keperluan itu bersifat universal dan kesihatan dan kelangsungan hidup adalah penting.

Burton (1990) pula mengaitkan keperluan dengan keadaan sosial dan politik semasa melihat bagaimana keperluan manusia sejagat sering kali diabaikan akibat konflik sosial. Terdapat sembilan jenis keperluan, iaitu keselamatan, kepunyaan 
atau kasih, menghargai diri, penghargaan diri, identiti, keselamatan kebudayaan, kebebasan, pengagihan keadilan, dan penyertaan. Max-Neef (1992) yang merupakan seorang ahli ekonomi, menggunakan pendekatan yang berfokus pada kepuasan terhadap keperluan manusia yang berhubung kait dengan bahagian tertentu, tahap keupayaan bagi pertumbuhan generasi, dan lain-lain lagi. Beliau juga mengandaikan tidak ada keperluan yang lebih penting berbanding lain seperti yang dihujahkan oleh Abraham Maslow kerana setiap keperluan itu mempunyai kepentingan dan makna pada kehidupan manusia. Keperluan yang difokuskan oleh beliau terbahagi kepada sembilan, iaitu jumlah keperluan asas yang diperlukan untuk hidup, penjagaan, perasaan kasih, memahami, penyertaan, masa lapang, penghasilan, identiti, kebebasan.

Dapatan yang diketengahkan menunjukkan bahawa keperluan setiap individu mahupun masyarakat boleh berbeza; antaranya berdasarkan lingkungan situasi persekitaran semasa. Lingkungan ini boleh merujuk keadaan ekonomi negara atau keluarga dan juga kestabilan politik. Namun demikian, kebanyakan kajian yang dilakukan terhad pada keperluan dalam bentuk kelangsungan hidup atau kemandirian khususnya keperluan asas, tanpa mengambil kira keperluan lain yang melibatkan perhubungan dan interaksi sesama masyarakat yang mampu memberikan kesan terhadap perbelanjaan seharian golongan belia B40 dan M40 ini.

\section{KERANGKA KAJIAN}

Bagi membangunkan model keperluan manusia yang merangkumi aspek material dan bukan material bersesuaian dengan konteks kajian; iaitu masyarakat bandar, kajian ini menggunakan pendekatan ekonomi yang diperkenalkan oleh Max-Neef. Pemilihan pendekatan ini disokong antaranya oleh kajian yang telah dilakukan oleh Murray et al. (2005) dan juga Barreiro (2006) melalui tesis doktor falsafahnya. Mereka melihat teori yang diperkenalkan oleh Max-Neef telah menyumbang kepada pencerahan permasalahan secara konseptual mengenai keperluan yang berkait rapat dengan kualiti hidup dan pembangunan polisi.

Jika sebelum ini keperluan asas sering digunakan dalam kajian ekonomi, MaxNeef memformulasi teori keperluan untuk mengatasi kekurangan dalam pendekatan keperluan yang sedia ada kerana pendekatan keperluan asas mengehadkan pemahaman mengenai keperluan sebenar manusia. Prinsipnya, teori keperluan adalah tentang manusia dan bukan merujuk barangan semata-mata. Selain itu, keperluan dan kecukupan juga dilihat sebagai dua kumpulan yang berbeza. Ketika 
pengkaji terdahulu merujuk keperluan itu tidak terbatas, beliau beranggapan sebaliknya. Variasi dan kepelbagaian budaya bukan disebabkan oleh perbezaan keperluan namun, perbezaan kepuasan yang memberikan mereka rasa cukup melalui penggunaan keperluan yang diperoleh, kerana, keperluan juga berhubungan dengan kecukupan. Seseorang itu mampu memenuhi pelbagai keperluan namun, kadangkala untuk memenuhi sesuatu keperluan, terdapat pelbagai kecukupan yang perlu dipenuhi.

Oleh itu, pendekatan yang digunakan oleh Max-Neef yang meliputi keperluan fisiologi dan sosiologi (material dan bukan material) dilihat amat bersesuaian dengan konteks kajian ini. Walau bagaimanapun, daripada sembilan keperluan tersebut, hanya lima keperluan sahaja yang akan diguna pakai dalam kajian ini. Lima keperluan tersebut ialah keperluan asas (KE1), perlindungan dan kesihatan (KE2), keluarga (KE3), identiti keagamaan (KE4) dan masa lapang (KE5) seperti yang dapat dilihat dalam Jadual 1.

Pemilihan keperluan seperti yang telah dinyatakan tersebut disandarkan atas beberapa faktor. Bagi item memahami, item tersebut lebih memfokuskan sistem yang perlu ada dalam hubungan antara dua individu, contohnya teknik atau kemahiran dan perkara ini tidak melibatkan konteks kajian. Bagi item penciptaan pula, item ini lebih menjurus kepada produktiviti seseorang dalam satu-satu organisasi atau kumpulan dan turut tidak menjurus kepada isu perbelanjaan yang dilakukan. Item kebebasan pula lebih berfokus pada keperluan hak sama rata, iaitu bagaimana untuk mendapatkan kelebihan atas diri sendiri berbanding dengan orang lain. Item ini juga

Jadual 1 Keperluan berdasarkan kerangka kajian.

\begin{tabular}{ll}
\hline Keperluan Berdasarkan Max-Neef & \multicolumn{1}{c}{ Pengubahsuaian } \\
\hline 1. Keperluan asas untuk hidup & 1. Keperluan asas (KE1) \\
2. Perlindungan & 2. Perlindungan dan kesihatan (KE2) \\
3. Perasaan kasih & 3. Keluarga (KE3) \\
4. Memahami & 4. Identiti keagamaan (KE4) \\
5. Penyertaan & 5. Masa lapang (KE5) \\
6. Masa lapang & \\
7. Penciptaan & \\
8. Identiti & \\
9. Kebebasan & \\
\hline
\end{tabular}


MELAYU: JURNAL ANTARABANGSA DUNIA MELAYU JILID 14 BIL. 1 JANUARI 2021

tidak berkaitan dengan konteks kajian kerana lebih menjurus kepada persaingan dalam satu-satu organisasi.

\section{METODOLOGI KAJIAN}

Kajian ini bertujuan untuk melihat keutamaan ketika berbelanja yang dilakukan golongan belia Melayu yang tergolong dalam kumpulan B40, iaitu RM3900 ke bawah, dan kumpulan, M40, iaitu berpendapatan antara RM3900 ke atas hingga RM8000.

Dalam kajian ini, teknik pensampelan bertujuan digunakan untuk menentukan kriteria responden yang sesuai dengan keperluan kajian. Responden dalam kajian ini terdiri daripada golongan belia yang berumur antara 20 hingga 39 tahun, bekerja dan menetap di Kuala Lumpur. Lingkungan umur 20 hingga 39 tahun dipilih kerana golongan belia ketika ini diandaikan sudahpun bekerja dan sedang memperbaik kehidupan. Edaran borang soal selidik kemudiannya telah dilaksanakan sekitar bulan September hingga November 2017. Daripada 550 edaran borang soal selidik yang telah telah dilakukan di sekitar kawasan Kuala Lumpur, hanya 522 yang boleh diguna pakai manakala selebihnya telah rosak. Bagi membandingkan aras kesignifikanan keperluan yang dikaji bagi dua kumpulan, iaitu belia B40 dan M40, ujian Mann-Whitney akan digunakan. Di samping itu, kaedah analisis Structural Equation Modelling (SEM) turut dilaksanakan bagi menentukan keperluan yang diberikan perhatian oleh kedua-dua kumpulan ketika memenuhi perbelanjaan.

\section{PERBINCANGAN HASIL DAPATAN KAJIAN}

Analisis secara deskriptif dijalankan bagi meninjau latar belakang responden yang terlibat dalam kajian ini. 522 orang responden yang terlibat merupakan kaum Melayu yang menetap di kawasan Kuala Lumpur. Berdasarkan edaran soal selidik yang telah dilaksanakan, analisis deskriptif yang dilakukan menunjukkan bahawa daripada keseluruhan responden $(\mathrm{N}=522)$, lebih daripada separuh iaitu 57\% responden ialah wanita. Kumpulan umur yang terlibat bagi kajian ini dibahagikan kepada dua golongan, iaitu (1) berumur antara 20 hingga 29 tahun, dan (2), 30 hingga 39 tahun. Lebih daripada separuh, iaitu 68\% daripada responden tergolong dalam kumpulan umur 20 hingga 29 tahun.

Bagi status perkahwinan, terdapat empat kumpulan status yang digunakan, iaitu (1) berkahwin, (2) berkahwin dan mempunyai anak, (3) berkahwin dan tiada anak, dan (4) bercerai atau bapa atau ibu tunggal. Analisis menunjukkan bahawa $61 \%$ 
POLA PERBELANJAAN BELIA MELAYU B40 DAN M40 DI KUALA LUMPUR

daripada responden ialah bujang, 21\% telah berkahwin dan mempunyai anak, $11 \%$ berkahwin dan tiada anak manakala $1 \%$ telah bercerai atau bapa atau ibu tunggal.

Bagi tahap pendidikan tertinggi yang diperoleh, hampir separuh daripada responden memiliki Ijazah Sarjana Muda, iaitu 43\%, 28\% yang lainnya memiliki Sijil Tinggi Pelajaran Malaysia (STPM) atau Diploma dan setaraf, 18\% memiliki Sijil Pendidikan Malaysia (SPM), manakala Penilaian Menengah Rendah (PMR) dan lain-lain masing-masing sebanyak $2 \%$. Selain tu, terdapat $7 \%$ daripada responden yang memiliki ijazah lanjutan.

\section{Perbandingan Pola Perbelanjaan Kumpulan B40 Dan M40}

Berdasarkan ujian Mann-Whitney seperti Jadual 2, tidak terdapat perbezaan yang signifikan bagi keperluan yang dikaji, iaitu keperluan asas (KE1) $(\mathrm{U}=16109.0, \mathrm{Z}$ $=-1.267, \mathrm{p}=>0.05)$, perlindungan dan kesihatan (KE2), $(\mathrm{U}=15527.5, \mathrm{Z}=-1.735$, $\mathrm{p}>0.05)$ keluarga $(\mathrm{KE} 3)(\mathrm{U}=17517.5, \mathrm{Z}=-0.137, \mathrm{p}=>0.05)$ identiti keagamaan $(\mathrm{KE} 4)(\mathrm{U}=17336.0, \mathrm{Z}=-0.290, \mathrm{p}>0.05)$ dan keperluan masa lapang $(\mathrm{KE} 5)(\mathrm{U}=$ 16446.5, $\mathrm{Z}=-1.033, \mathrm{p}>0.05)$.

Tiada perbezaan yang signifikan menandakan perbelanjaan antara keduadua kumpulan pendapatan adalah sama. Maka, kajian ini akan membincangkan perbelanjaan secara menyeluruh merentas kumpulan pendapatan menggunakan analisis Structural Equation Modelling (SEM) yang melihat perhubungan antara jumlah perbelanjaan secara keseluruhan terhadap tiap satu pola perbelanjaan, iaitu keperluan asas (KE1), perlindungan dan kesihatan (KE2), keluarga (KE3), identiti keagamaan (KE4) dan masa lapang (KE5). Hasil analisis kajian ini mendapati, golongan belia Melayu di Kuala Lumpur sama ada dalam kumpulan B40 ataupun M40, memberikan perhatian kepada keperluan perlindungan dan kesihatan jika berlaku perubahan dalam pola perbelanjaan yang sedang diamalkan.

Jadual 2 Ujian statistik Mann-Whitney.

\begin{tabular}{|l|c|c|c|c|c|}
\hline Ujian Analisis & KE1 & KE2 & KE3 & KE4 & KE5 \\
\hline Mann-Whitney U & 16109.0 & 15527.5 & 17517.5 & 17336.0 & 16446.5 \\
\hline Wilcoxon W & 19349.0 & 113430.5 & 115420.5 & 20576.0 & 114349.5 \\
\hline Z & -1.267 & -1.735 & -0.137 & -0.290 & -1.033 \\
\hline Aras Signifikan & 0.205 & 0.083 & 0.891 & 0.772 & 0.301 \\
\hline
\end{tabular}


Terdapat beberapa dapatan baharu mengenai pola perbelanjaan belia Melayu di Kuala Lumpur yang telah ditemui. Pertama, perubahan pola perbelanjaan secara keseluruhannya memberikan kesan yang besar terhadap perbelanjaan bagi jenis keperluan yang diukur dalam kajian ini, iaitu keperluan asas $(\beta=0.642)$, perlindungan dan kesihatan $(\beta=0.657)$, keluarga $(\beta=0.562)$, identiti keagamaan $(\beta=0.507)$, dan masa lapang $(\beta=0.605)$. Namun demikian, setelah diteliti saiz kesan perubahan bagi setiap keperluan, keperluan bagi perlindungan dan kesihatan merupakan jenis perbelanjaan yang menerima kesan terbesar, diikuti keperluan asas, masa lapang, keluarga dan akhir sekali identiti keagamaan.

Sangkaan yang meleset mengenai wujudnya perbezaan dalam perbelanjaan oleh kedua-dua kumpulan pendapatan ini memperlihatkan satu penemuan baharu. Dapatan kajian ini bertentangan dengan pendapat Martins, et al. (2012) yang berandaian bahawa isi rumah yang berpendapatan rendah akan berbelanja lebih daripada pendapatan yang diperolehnya. Situasi kewangan ini seperti yang telah ditemui dalam kajian Husniyah et al. (2017), iaitu kumpulan yang berpendapatan rendah sekitar RM3,500 dan ke bawah berdepan dengan perbelanjaan yang tinggi dan mempunyai sumber kewangan untuk berbelanja yang sangat terhad. Dengan merujuk laporan yang dikeluarkan oleh Bank Negara (2015) berdasarkan Penyiasatan Pendapatan Isi Rumah dan Kemudahan Asas 2014 dan 2009; dan Penyiasatan Perbelanjaan Isi Rumah 2014 dan 2009, dapatan ini selari dengan data yang telah diketengahkan, iaitu, tidak banyak perbezaan mengenai tingkat perbelanjaan yang dilakukan berdasarkan jumlah pendapatan yang diterima.

Keadaan ini bermakna, individu dalam kumpulan B40 dan M40 mengamalkan bentuk perbelanjaan yang hampir sama walaupun berlainan tingkat pendapatan.

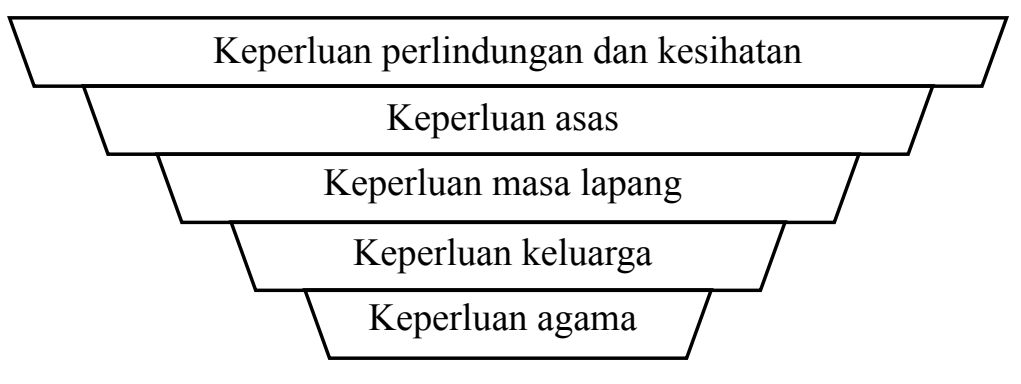

Keperluan mengikut keutamaan daripada penting kepada kurang penting

Rajah 1 Pola perbelanjaan belia B40 dan M40 mengikut keperluan tertentu. 
Tambahan lagi, kenyataan Creek (1959: 84), iaitu harga tidak lagi merupakan perkara yang penting ketika membuat keputusan dalam perbelanjaan apabila ahli keluarga mempunyai pendapatan yang semakin meningkat kerana secara tidak langsung, kuasa membeli akan dapat dipertingkatkan, tidak terpakai dalam konteks kajian tentang perbelanjaan kumpulan B40 dan M40 di bandar.

Rajah 1 menunjukkan, perbelanjaan bagi keperluan perlindungan dan kesihatan merupakan perbelanjaan utama yang diberikan perhatian berbanding dengan keperluan asas masa lapang, keluarga, dan agama. Penemuan ini bertentangan teori yang dikemukakan oleh Maslow (1943), dan pendapat Solomon (1996) mengenai keperluan asas yang menjadi keutamaan berbanding keperluan lain.

Di samping itu, kajian ini turut tidak bersependapat dengan kenyataan MaxNeef (1992) yang merasakan tiada keperluan yang lebih berkuasa (superior) berbanding keperluan yang lain. Namun begitu, dapatan kajian ini bersependapat dengan kenyataan yang dikeluarkan oleh Creek (1959) yang perbelanjaan mengikut keutamaan akan berubah atas sebab-sebab tertentu. Apabila dihimpit dengan kekangan sumber kewangan untuk berbelanja bagi memenuhi keperluan, mereka terpaksa membuat pilihan untuk menentukan jenis perbelanjaan bagi keperluan manakah yang perlu diberikan perhatian terlebih dahulu.

\section{KEPERLUAN PERLINDUNGAN DAN KESIHATAN}

Dapatan kajian ini menemukan, keperluan perlindungan dan kesihatan diutamakan apabila berlaku rombakan perbelanjaan. Perbelanjaan kesihatan akan sentiasa meningkat kerana peningkatan kos perbelanjaannya ditentukan oleh faktorfaktor perubahan teknologi, subsidi insurans, pertumbuhan penduduk dan juga kekangan sumber. Oleh itu, kemampuan pendapatan menjadi faktor penentu yang mempengaruhi perbelanjaan kesihatan secara signifikan (Nor Aini Idris et al., 2011).

Murallitharan Munisamy et al. (2018) yang memetik dapatan daripada World Health Organization (WHO) berpendapat, perbelanjaan bagi keperluan kesihatan sememangnya merupakan isu yang penting lebih-lebih lagi bagi kumpulan pendapatan terendah dan pertengahan kerana mereka menggunakan kaedah out-of-pocket (OOP) untuk membayar perbelanjaan bagi keperluan kesihatan. Kenyataan ini seperti yang telah dibuktikan menerusi kajian Husniyah et al. (2017) yang menggariskan bahawa simpanan berkorelasi secara signifikan dengan kewangan bagi keperluan kesihatan. Individu yang berdepan dengan masalah kesihatan akan berbelanja lebih tinggi untuk menangani risiko masalah kesihatan agar mendapat kehidupan yang sejahtera. Individu yang sihat akan berbelanja secara minimum untuk menjaga kesihatan, 
maka mereka akan berpeluang untuk menyimpan wang bagi mendapatkan kewangan kesihatan yang lebih baik.

Dapatan ini seperti yang telah diketengahkan oleh Husniyah et al. (2017) yang telah melihat hubungan kewangan kesihatan dengan sektor pekerjaan dan umur, iaitu pekerja yang lebih berusia dan berpendapatan lebih tinggi mempunyai kewangan kesihatan yang lebih baik berbanding dengan pekerja yang muda dan tergolong dalam kumpulan berpendapatan rendah. Terdapat beberapa andaian mengenai kecenderungan perbelanjaan golongan belia bagi keperluan ini. Meskipun klinik kesihatan kerajaan seperti klinik komuniti (dahulu dikenali sebagai Klinik 1Malaysia) banyak ditempatkan di kawasan penempatan kos rendah agar masyarakat sekitar mudah untuk mengakses kemudahan tersebut namun, kepadatan penduduk di kawasan kos rendah menyebabkan berlaku kesesakan di klinik tersebut. Hal ini didorong oleh sikap penduduk yang masing-masing ingin mendapatkan kos rawatan yang murah. Rentetan daripada itu, sebahagian penduduk terpaksa beralih ke klinik swasta yang kos rawatannya lebih mahal.

Keperluan perlindungan pula terdapat dalam beberapa bentuk seperti simpanan, pelaburan, dan aset. Bagi isu simpanan, di Malaysia, budaya menyimpan masih pada tahap rendah dan kurang dipraktikkan oleh golongan pekerja seperti yang dinyatakan oleh Husna Sulaiman dan Jariah Masud (2012: 241) "in Malaysia and other developing countries, savings and investments from the income earned earlier during one's working life are not common practices among the workers". Situasi ini mungkin disebabkan oleh tingkah laku berhutang yang tinggi dalam kalangan masyarakat bandar. Kesannya, lebihan wang tidak dapat disimpan, sebaliknya digunakan untuk membayar hutang.

Menerusi kajian yang dilakukan oleh Bank Negara Malaysia dan Gabungan Persatuan-Persatuan Pengguna Malaysia (FOMCA) (2017) yang menganalisis kadar hutang bagi golongan miskin bandar, hutang sewa beli kenderaan merupakan hutang yang paling banyak dilakukan $(41.9 \%)$, diikuti perumahan $(36.9 \%)$, peribadi (29.9\%), kad kredit (15.1\%), dan pendidikan (12.6\%). Hutang sewa beli kenderaan yang tinggi disokong dengan data yang diperoleh dari Persatuan Automotif Malaysia (MAA) yang menunjukkan bahawa hutang jenis ini banyak dibuat menjelang perayaan terutamanya Hari Raya Aidilfitri (Utusan Malaysia, 2016). Namun demikian, hutang yang dibuat masih rendah, dan Bank Negara (2018) mencatatkan hutang isi rumah semakin menurun antara suku pertama tahun 2015 hingga suku keempat tahun 2017. Keadaan ini disebabkan oleh tawaran kadar pinjaman oleh pihak bank kepada pelanggan yang lebih rendah bagi pembelian harta bukan kediaman dan pembiayaan peribadi. 
Walaupun budaya berhutang masih banyak diamalkan, mereka masih membuat simpanan dan pelaburan dalam beberapa bentuk. Bank Negara Malaysia dan Gabungan Persatuan-Persatuan Pengguna Malaysia (FOMCA) (2017) menyatakan golongan miskin bandar membuat simpanan dan pelaburan dalam Kumpulan Wang Simpanan Pekerja (KWSP), iaitu pelaburan tertinggi (67.7\%), disusuli dengan tabung haji (34.5\%), investment link (18.2), dan saham amanah (15.9\%).

Susulan daripada peratusan simpanan bagi KWSP yang tinggi, yang tujuannya sebagai "tabung pencen" yang membuktikan bahawa kaedah ini merupakan kaedah dan pilihan oleh kebanyakan pekerja. Namun begitu, budaya menyimpan dalam KWSP ini amat perlu diberikan perhatian. Kajian yang dilakukan oleh KWSP menunjukkan golongan pesara mampu menghabiskan simpanannya dalam masa tiga tahun selepas persaraan.

Dengan peningkatan jangkaan hayat di Malaysia, iaitu 77.4 tahun bagi perempuan dan 72.7 tahun bagi lelaki (Jabatan Perangkaan Malaysia, 2017), dan diandaikan seseorang itu mampu hidup hingga sampai usia 75 tahun (Malaysiakini, 2017), ditambah dengan simpanan yang sedikit, sudah tentu amat membebankan mereka kelak. Apabila telah bersara, rakyat Malaysia dijangka akan hidup 15 tahun lagi dan sudah tentu simpanan KWSP, wang persaraan dan simpanan peribadi menjadi sandaran dan punca kebergantungan mereka untuk meneruskan kehidupan (Suhaimi \& Norma, 2013; The Star, 2018).

Keperluan untuk kesihatan yang merangkumi ubat-ubatan, suplemen yang lebih banyak diperlukan ketika sudah tua berbanding pada usia muda akan menyebabkan wang lebih banyak dibelanjakan bagi keperluan ini. Mahu tidak mahu, dengan pertambahan keperluan yang tidak boleh diketepikan apabila sudah tua kelak, memaksa mereka mengecilkan perbelanjaan bagi keperluan lain seperti membaiki dan membeli rumah serta menunaikan haji.

Situasi kewangan masa hadapan ini menerangkan kemungkinan yang akan berlaku jika kepentingan sekuriti sosial kurang diberikan perhatian. Atas kesedaran mengenai isu ini, golongan belia Melayu bandar dijangka ingin meningkatkan perbelanjaan bagi keperluan perlindungan dan kesihatan. Mereka berasa yakin bahawa sekuriti sosial yang tinggi akan membantu mereka untuk menjalani kehidupan yang lebih baik pada masa akan datang. Jika mereka ditimpa kemalangan atau didiagnosis dengan penyakit yang memerlukan kos yang tinggi, insurans kesihatan yang dilanggani akan membayar kos perubatan tersebut. Oleh itu, mereka tidak perlu bersusah-payah menggadai dan meminjam wang bagi melunaskan kos itu. Di samping itu, dengan membuat simpanan bagi keperluan masa depan, mereka boleh menggunakannya apabila ditimpa sesuatu kecemasan. 


\section{KEPERLUAN ASAS}

Ketika kemampuan untuk memenuhi keperluan asas menjadi penentu bagi menjalani kehidupan seharian yang lebih selesa, perbelanjaan untuk memenuhi keperluan asas tidak lagi menjadi keutamaan. Hal ini disebabkan oleh harga keperluan asas, iaitu rumah, barangan keperluan asas, pakaian dan pengangkutan (termasuk kos petrol) di bandar yang meningkat, hari demi hari.

Penarikan subsidi bagi barangan keperluan asas turut menyebabkan berlaku peningkatan harga contohnya bagi minyak masak. Harga minyak masak telah melonjak naik hingga 60\%, iaitu dari RM14.70 kepada RM23.70 bagi botol 5 kilogram (Malaysiakini, 2016). Peningkatan harga minyak masak ini secara relatifnya turut meningkatkan harga makanan di restoran. Secara tidak langsung, turut meningkatkan perbelanjaan isi rumah secara keseluruhan khususnya bagi keperluan makanan kerana perbelanjaan isi rumah bagi makan di luar adalah lebih tinggi berbanding makan di rumah (Jabatan Perangkaan Malaysia, 2017).

Di samping isu mengenai harga makanan, lambakan servis penghantaran makanan membuktikan bahawa secara tidak langsung menyebabkan perbelanjaan makanan di luar rumah turut meningkat. Peningkatan perkhidmatan ini sudah tentu disebabkan oleh permintaan pelanggan. Berdasarkan carian di enjin untuk mencari aplikasi seperti PlayStore dan AppStore, terdapat pelbagai syarikat yang menawarkan servis menghantar makanan seperti Foodpanda, dahmakan, mammam, DeliverEat, honestbee, GrabFood, Deliveroo, dan Bungkusit. Syarikat ini tidak termasuk dengan servis yang sememangnya telah ditawarkan oleh syarikat makanan segera seperti Kentucky Fried Chicken (KFC), McDonalds, Dominos, dan Pizza Hut. Malah, terdapat juga premis makanan di sekitar kawasan perumahan yang turut menawarkan perkhidmatan menghantar makanan, sama ada dengan caj yang rendah ataupun tanpa caj bergantung pada jumlah makanan yang dipesan.

Servis penghantaran makanan juga tidak terhad untuk makanan siap, malahan

ada perkhidmatan penghantaran bagi pesanan barangan sejuk beku dan "barang keperluan dapur" seperti yang ditawarkan syarikat penghantaran HappyFresh dan juga perkhidmatan yang dilakukan oleh syarikat TESCO bagi memudahkan pelanggan memesan barang dan mendapatkannya berdasarkan waktu penghantaran yang dipilih. Selain itu, terdapat juga servis sebagai "personal shopper". Mereka membantu untuk membelikan barang keperluan dapur seperti yang diperlukan dengan kadar bayaran servis yang rendah antara RM5 hingga RM10 bergantung pada jarak lokasi. Kemudahan yang pelbagai seperti yang dibincangkan menunjukkan bahawa servis yang lebih banyak ditawarkan menyebabkan peningkatan keperluan bagi 
makanan di luar rumah, yang secara tidak langsung turut meningkatkan keseluruhan perbelanjaan harian penduduk bandar.

Dalam isu perumahan pula, walaupun rumah merupakan keperluan utama, harga di luar kemampuan menyukarkan penduduk di bandar untuk memilikinya, baik secara pemilikan mahupun sewaan. Walaupun pihak kerajaan telah melaksanakan dasar untuk membina rumah kos rendah dengan harga antara RM25,000 sehingga RM42,000 seunit yang bergantung pada lokasi, dan kelayakan untuk membeli dihadkan kepada golongan yang berpendapatan antara RM750.00 hingga RM1,500.00 sebulan, namun, unit rumah kos rendah yang ditawarkan adalah sangat terhad berbanding dengan jumlah permintaan (Abdul Rahman, 2011). Walaupun kumpulan yang berpendapatan sederhana tidak layak untuk membeli rumah kos rendah dan tidak mampu pula untuk membeli rumah harga tinggi, rumah di bawah harga RM300,000 tidak ada atau kurang dalam pasaran Kuala Lumpur. Permasalahan ini juga berpunca daripada kesan pembangunan di sekitar Kuala Lumpur yang banyak memfokuskan pembinaan bandar-bandar baharu, premis ruang kerja dan hab bagi industri dan komersial. Pembinaan ini secara tidak langsung meningkatkan populasi penduduk di bandar dan dalam masa yang sama mengecilkan kawasan bagi tujuan pembinaan perumahan (Wan Nor Azriyati et al., 2011).

Bagi mendapatkan maklumat mengenai harga semasa bagi sewaan rumah, tinjauan yang dilakukan menerusi laman sesawang Mudah.my, Mudah Property dan iBilik yang menjadi platform pengiklanan untuk mencari rumah dan bilik sewa sekitar Kuala Lumpur mencatatkan, bagi rumah yang mempunyai 3 bilik tidur dan 2 bilik air dengan keluasan lantai antara 1000 hingga 1400 kaki persegi, harga sewaan adalah antara RM1700 hingga RM2200 dan ke atas. Bagi sewaan mengikut bilik, harga bilik utama adalah sekitar RM500 hingga RM650, bilik sederhana pula antara RM400-RM550, manakala bilik kecil pula sekitar RM350 dan ke atas.

Bagi rumah yang mempunyai 3 bilik tidur dan 2 bilik air dengan keluasan lantai 600 hingga 926 kaki persegi pula, harga sewaan adalah antara RM600 hingga RM1400 malahan, turut ada yang menawarkan harga mencecah RM1500. Kadar sewaan mengikut bilik pula, didapati harga bilik utama adalah antara RM300 hingga RM450, bilik sederhana pula antara RM280 hingga RM350, manakala bilik kecil antara RM170 hingga RM250. Harga yang ditawarkan turut bergantung sama ada berperabot, berperabot sebahagian, atau tanpa perabot, selain berbeza mengikut kemudahan yang tersedia di dalam dan sekitar kawasan perumahan seperti kolam renang, gimnasium, hentian Aliran Transit Ringan (LRT), bas henti-henti, dan tempat letak kenderaan. Kebiasaannya kawasan perumahan yang mudah untuk mengakses pengangkutan awam akan ditawarkan dengan harga yang lebih tinggi. 
Untuk menguatkan lagi isu perbelanjaan dan tahap kemampuan belia di bandar, dilema dan kesusahan yang dihadapi penduduk bandar akibat kos sara hidup yang meningkat, keadaan ini disokong dengan laporan tahunan oleh Bank Negara (2017) menekankan bahawa mereka terutamanya golongan bujang memerlukan sekurangkurangnya RM2700 sebulan untuk meneruskan kelangsungan hidup di Kuala Lumpur. Bagi pasangan berkahwin tanpa anak pula ialah sebanyak RM4500 dan pasangan berkahwin dengan dua orang anak sebanyak RM6500.

\section{KEPERLUAN MASA LAPANG}

Keperluan masa lapang melibatkan perbelanjaan untuk aktiviti yang dilakukan pada masa senggang seperti sewaan dan pembelian peralatan, tiket hiburan, dan lain-lain lagi. Kebiasaannya, aktiviti masa lapang dilakukan pada hujung minggu, dan cuti umum. Aktiviti masa senggang boleh dianggap sebagai keperluan escapism untuk keluar dan lari sebentar daripada masalah dan tekanan kerja, seperti yang dinyatakan oleh Stockhausen (1998: 1675) "leisure as non-work activity that contributes to the health and wholeness of a person".

Kajian ini menunjukkan bahawa keperluan masa lapang tidak menjadi keutamaan dan akan dipenuhi jika keperluan perlindungan dan kesihatan; dan keperluan asas dapat disediakan. Dapatan ini selari dengan laporan Penyiasatan Perbelanjaan Isi Rumah (2016) yang menunjukkan perbelanjaan bagi keperluan rekreasi dan kebudayaan merupakan perbelanjaan kedua terkecil.

Di bandar, kos sara hidup yang tinggi memaksa warga bandar untuk bekerja keras demi mendapatkan pendapatan yang lebih tinggi agar keperluan asas dapat dipenuhi. Perkhidmatan e-hailing yang semakin bertambah membuktikan bahawa permintaan bagi pekerjaan tambahan semakin meningkat. Berdasarkan tinjauan di laman sesawang atas talian, antara perkhidmatan e-hailing yang terkemuka di Malaysia ialah Grab dan UBER (perkhidmatan UBER telah dimansuhkan di Asia Tenggara). Selain itu, syarikat e-hailing lain yang dilihat ingin bersaing dengan syarikat terkemuka sedia ada antaranya termasuklah MyCar, Diffride, Jomrides, MULA, Dacsee, Riding Pink, PICKnGO, EZCab, Tumpang, Quulo, Zeepon, dan Frenzt. Setiap satu syarikat ini menawarkan faedah yang menarik untuk merekrut pemandu antaranya seperti yang dilakukan oleh syarikat Diffride. Syarikat ini hanya mengenakan yuran sebanyak RM5 dan pendapatan yang diperoleh selebihnya akan dapat dinikmati sepenuhnya oleh pemandu itu sendiri.

Tanpa disedari, pelbagai tawaran untuk merebut peluang menggandakan pendapatan ini menyebabkan keperluan masa lapang kurang diberikan perhatian. 
Data ini disokong dengan laporan Institut Kajian Khazanah (2018) yang menyatakan bahawa pendapatan daripada pekerjaan sendiri menyumbang sebanyak $15.6 \%$ daripada keseluruhan pendapatan yang diperoleh bagi tahun 2016, dan jumlah ini adalah lebih tinggi berbanding pendapatan daripada pelaburan dan pindahan wang contohnya bantuan kewangan daripada pihak kerajaan seperti Bantuan Sara Hidup (dahulu dikenali sebagai Bantuan Rakyat 1Malaysia) dan juga daripada ahli keluarga.

Keperluan ini merupakan keperluan yang agak penting kerana berfungsi untuk kesejahteraan hidup. Namun demikian, jika mereka berasa mereka tidak dapat menampung keperluan perbelanjaan semasa, mencari atau melakukan kerja tambahan merupakan alternatif lain bagi kebanyakan isi rumah. Malah ada yang terpaksa melakukan lebih daripada satu pekerjaan. Siang bekerja di pejabat, manakala malam pula membuat perkhidmatan e-hailing. Kesan kesibukan bekerja, suami isteri dan ibu bapa tidak mempunyai masa yang berkualiti bersama-sama ahli keluarga. (Bank Negara Malaysia \& Gabungan Persatuan-Persatuan Pengguna Malaysia (FOMCA), 2017).

Akibat kekangan masa untuk menjalankan aktiviti masa lapang di luar rumah, keadaan ini mewujudkan satu bentuk hiburan di rumah (in-house entertainment). Kenyataan ini disokong dengan kemunculan aplikasi seperti Netflix, iflix, Viu, dan Astro First. Aplikasi ini memberi pilihan kepada pengguna untuk memilih rancangan atau filem kegemaran mereka mengikut negara. Sebagai contoh, Astro First menjadi platform yang membawa filem baharu ke siaran televisyen di rumah sama ada filem dari luar negara mahupun filem tempatan. Variasi pilihan filem yang ditawarkan ini membolehkan pengguna "menonton wayang" hanya dari rumah dengan bayaran yang lebih murah, iaitu antara RM10-RM15, bergantung pada jenis filem. Filem ini juga dapat ditonton berulang kali dalam tempoh seminggu. Begitu juga dengan aplikasi "tonton" yang memudahkan isi rumah menonton semula drama-drama yang diminati secara atas talian dengan bayaran RM10 sebulan atau RM96 bagi tempoh setahun.

Dapatan ini menunjukkan bahawa terdapat belia yang terpaksa mengetepikan keinginan untuk berhibur dan beriadah di luar rumah akibat kekangan masa dan persekitaran yang sesak. Keadaan ini didorong atas faktor keinginan untuk menikmati cuti yang berkualiti bersama-sama rakan ataupun keluarga. Tidak kurang juga, dapatan ini menunjukkan bahawa belia banyak menghabiskan masa bersama rakanrakan di alam siber kerana masa lapang yang ada dihabiskan untuk meluangkan masa bersama pasangan. 


\section{KEPERLUAN KELUARGA}

Andaian awal kajian ini bahawa golongan belia Melayu tetap mengambil tahu keperluan keluarga (ibu bapa dan adik beradik) walaupun tinggal secara berasingan, meleset sama sekali. Dapatan kajian memperlihatkan keperluan keluarga diutamakan hanya setelah keperluan masa lapang dipenuhi. Jika merujuk kembali sumbangan wang daripada anak-anak kepada ibu bapa, jumlahnya hanya sebahagian kecil daripada peratusan punca pendapatan ibu bapa berbanding dengan pendapatan yang lain (Husna \& Jariah, 2012). Meskipun ibu bapa mungkin mempunyai simpanan sendiri yang diperoleh daripada simpanan KWSP atau pelaburan unit amanah yang dilakukan, sumbangan wang daripada anak-anak masih pada tahap yang sangat rendah.

Ironinya, bagi ibu bapa yang tidak mempunyai aset lain, sudah tentu ketiadaan sumber kewangan daripada anak-anak akan menambah kesukaran mereka untuk memenuhi keperluan. Namun begitu, ditinjau dari persekitaran sosial pada masa kini, tidak semua warga tua mengharapkan sumbangan wang daripada anakanak kerana terdapat juga warga tua yang bekerja untuk menampung sebahagian perbelanjaan mereka. Tinjauan yang dilakukan di premis restoran segera sekitar kawasan Kuala Lumpur, selain penggajian kepada Orang Kelainan Upaya (OKU), terdapat juga warga tua berumur 50 tahun ke atas bekerja di premis tersebut sehingga larut malam. Jika peluang pekerjaan di sekitar kawasan perumahan mereka sukar diperoleh, permasalahan kewangan akan semakin meruncing selari dengan yang dinyatakan Husna dan Jariah, (2012), iaitu pekerjaan bagi menyokong pendapatan golongan pesara amatlah penting untuk membantu penyediaan barangan keperluan di rumah.

Dalamhubungankekeluargaan, sememangnya anak-anak dipertanggungjawabkan untuk menjaga ibu bapa. Melewati usia, ibu bapa akan banyak menghabiskan masa untuk aktiviti keagamaan dan sukarela (Husna \& Jariah, 2012: 241). Namun begitu, dengan kos sara hidup yang tinggi di bandar dan perbelanjaan sedia ada yang semakin meningkat, anak-anak tidak mampu untuk menghantar wang yang banyak ke kampung kerana tinggal berasingan memerlukan peruntukan perbelanjaan yang lebih besar berbanding tinggal bersama.

\section{KEPERLUAN IDENTITI KEAGAMAAN}

Agama Islam mengajar bahawa dalam setiap pendapatan yang diperoleh, terdapat bahagian yang perlu dibelanjakan untuk orang lain. Selain itu, Allah turut 
menjanjikan bahawa setiap satu yang kita belanjakan kepada orang lain, kita akan mendapat pulangan sebanyak 700 kali ganda. Terdapat tiga jenis pemberian untuk keperluan orang lain, iaitu zakat, sedekah, dan wakaf (Syadiyah et al. 2016). Zakat merujuk tanggungjawab secara kebajikan untuk membantu masyarakat Islam yang lain; yang dikira berdasarkan 2.5\% daripada hasil kekayaan secara tahunan. Sedekah pula merupakan perbuatan secara sukarela dan tidak semestinya melibatkan wang di samping penerimanya tidak terhad kepada orang Islam. Wakaf pula ialah harta yang derma bagi keperluan orang lain, dan bersifat kekal. Di samping perbelanjaan seperti yang telah dinyatakan, perbelanjaan bagi mengikuti kelas agama, ceramah, dan peralatan sembahyang turut dianggap sebagai sebahagian daripada perbelanjaan keagamaan yang digunakan dalam konteks kajian ini.

Orang Melayu mempercayai bahawa terdapat banyak kebaikan jika berbuat baik dan berbelanja atas orang lain antaranya mendapat keredaan, rahmat daripada Allah, dan dimurahkan rezeki (Syadiyah et al, 2016). Ganjaran berbuat baik kepada orang lain turut dipersetujui oleh masyarakat Barat, iaitu dapat memberi kepuasan dan kebahagiaan kepada si pelaku (Dunn \& Norton, 2014).

Malangnya, hasil kajian mendapati golongan B40 dan M40 di bandar kurang mementingkan keperluan agama. Dapatan yang menyatakan berpendapatan tinggi lebih banyak melibatkan diri dengan aktiviti kebajikan berbanding dengan golongan berpendapatan rendah (Lee \& Chang, 2007; Syadiyah et al. 2016) dilihat tidak selari dengan dapatan kajian ini.

Dapatan yang tidak konsisten dengan dapatan terdahulu menunjukkan, terdapat ruang kajian yang mungkin tidak dimasukkan dalam kajian antaranya kesan pembandaran dan kos sara hidup. Kesibukan bekerja, sumber pendapatan yang sedikit, dan keperluan yang pelbagai menyebabkan peruntukan kewangan bagi keperluan ini diendahkan sama ada secara sedar ataupun tidak.

Secara rasional, apabila dihimpit dengan kesusahan hidup, kita akan mendekatkan diri dengan Tuhan dan mengamalkan ajaran agama agar keberkatan dan kesenangan hidup dapat dinikmati. Sebaliknya, hal ini tidak dilakukan oleh golongan belia B40 dan M40 di bandar. Dapatan ini memberikan dimensi baharu dalam kajian mengenai perbelanjaan keagamaan, iaitu kesibukan dengan urusan dunia, kesempitan hidup, dan keraguan tentang kepada golongan manakah wang sumbangan tersebut akan sampai, menyebabkan penduduk bandar kurang menitikberatkan kepentingan keperluan agama dalam kehidupan. 


\section{KESIMPULAN}

Secara keseluruhannya, kajian ini ingin melihat perbelanjaan yang menjadi amalan belia kumpulan B40 dan M40 yang menetap di bandar. Berdasarkan dapatan daripada kajian lapangan, keperluan yang menjadi keutamaan kedua-dua kumpulan belia ketika berbelanja telah memperlihatkan satu dimensi baharu dan menyumbang kepada dapatan kajian mengenai isu perbelanjaan dan budaya berbelanja. Dapatan kajian menunjukkan, persekitaran kehidupan dan pendapatan yang terhad membentuk perbelanjaan yang mengutamakan kelangsungan survival. Dalam konteks kajian ini, keperluan tersebut ialah perlindungan dan kesihatan, dan juga keperluan asas.

Untuk mengharungi kehidupan di bandar yang penuh mencabar, sememangnya pertimbangan untuk mendahulukan keperluan yang paling penting amat dituntut. Hal ini sedemikian agar jumlah pendapatan yang dimiliki mencukupi untuk kehidupan seharian. Dapatan ini menunjukkan bahawa, walaupun keperluan asas seperti tempat tinggal merupakan keperluan paling utama namun, kos sara hidup yang tinggi di bandar memaksa golongan belia baik dalam kumpulan B40 mahupun M40 memilih untuk menyewa berbanding membeli. Maka tidak hairanlah jika, peruntukan perbelanjaan bagi keperluan perlindungan dan kesihatan umpamanya dapat dipertingkatkan dengan adanya lebihan wang hasil kos perbelanjaan bagi tujuan perumahan yang lebih rendah.

Namun begitu, kesibukan mencari wang juga menyebabkan keperluan masa lapang kurang dititikberatkan walaupun menetap di kawasan bandaryang menawarkan pelbagai bentuk hiburan. Kenyataan ini secara tidak langsung memperlihatkan tahap kelangsungan hidup yang tinggi bagi belia dalam kedua-dua kumpulan tersebut. Bagi keperluan keluarga, amalan dan nilai-nilai kekeluargaan yang berakar dalam kehidupan orang Melayu tidak menghalang golongan belia ini untuk terus berbakti kepada keluarga walaupun mempunyai pendapatan yang terhad.

Melalui dapatan tersebut, jelaslah bahawa perbelanjaan bagi memenuhi keperluan yang pelbagai dalam sesebuah kumpulan masyarakat itu diukur berdasarkan kepentingannya menurut masyarakat itu sendiri. Dengan adanya dapatan mengenai aspek perbelanjaan dari sudut hubungannya dengan pendapatan dan faktor sosial yang berjaya diketengahkan, dapatan ini dapat membantu pihak kerajaan untuk menyediakan polisi dan bantuan yang lebih bersasar, sesuai dengan realiti dan keinginan belia kumpulan B40 dan M40 yang menetap di bandar. Di samping itu juga, kajian ini membantu golongan belia menyusun keperluan mengikut kepentingannya, sesuai dengan struktur kehidupan di bandar di samping tingkat pendapatan mereka sendiri. Hasilnya, permasalahan sosial yang dijangka timbul ekoran isu perbelanjaan 
dapat ditangani dengan lebih baik seterusnya membantu golongan ini untuk menikmati kehidupan yang lebih sejahtera.

Dari segi teori, hasil kajian mendapati bahawa model sedia ada yang menerangkan jenis keperluan (Max-Neef, 1992) Human Scale Development menyediakan perincian yang sesuai untuk mengukur keperluan yang pelbagai. Olahan model tersebut disesuaikan dan digunakan dalam konteks masyarakat Melayu yang menyumbang kepada penambahbaikan model daripada beberapa aspek terutamanya aspek keluarga dan identiti keagamaan yang tidak banyak dikaji di Malaysia. Tambahan lagi, model yang telah ditambah baik ini memberikan tumpuan kepada perhubungan dalam masyarakat secara holistik bermula daripada institusi keluarga dan masyarakat sehinggalah persekitaran sosial.

Di samping itujuga, kajian ini memberikan satu pendekatan secara teoritikal untuk mengkaji perbelanjaan dengan melibatkan faktor-faktor yang mempengaruhinya; yang disesuaikan dengan budaya masyarakat Melayu. Hasil dapatan ini dapat membantu pihak kerajaan untuk membentuk polisi yang bersesuaian dengan keperluan kedua-dua tingkat pendapatan, khusus bagi golongan belia di bandar. Dari segi kaedah kajian pula, dengan SEM yang dianalisis menggunakan AMOS, kajian yang melihat perhubungan antara pemboleh ubah secara serentak lebih mudah dilaksanakan berbanding jika dilaksanakan menggunakan regresi. Di samping itu, kaedah ini turut memudahkan kajian yang mempunyai pemboleh ubah yang banyak dan saiz sampel yang besar (melebihi 300 orang).

Dapatan kajian ini memfokuskan isu perbelanjaan bagi keperluan tertentu yang berlingkaran dalam kehidupan belia kumpulan B40 dan M40 memandangkan mereka merupakan golongan yang amat terkesan dengan kos sara hidup di bandar dan yang secara tidak langsung mempengaruhi perbelanjaan. Bagi menambah baik kajian ini, kajian selanjutnya boleh memfokuskan faktor lain yang dijangka dapat menambah perincian mengenai isu perbelanjaan ini seperti persekitaran, gender, jenis kawasan penempatan dan tingkat pendapatan.

\section{PENGHARGAAN}

Artikel ini adalah sebahagian daripada hasil kajian di bawah geran penyelidikan Pusat Kajian Kecemerlangan Melayu (PKKM) Universiti Malaya. 
MELAYU: JURNAL ANTARABANGSA DUNIA MELAYU JILID 14 BIL. 1 JANUARI 2021

\section{RUJUKAN}

Abdul Rahman Embong. (2011). Pembandaran dan kehidupan bandar di semenanjung Malaysia. Akademika, 81(2), 23-39.

Ando, A., \& Modigliani, F. (1963). The "life cycle" hypothesis of saving: Aggregate implications and tests. The American Economic Review, 53(1), 55-84.

Bank Negara Malaysia \& Gabungan Persatuan-Persatuan Pengguna Malaysia (FOMCA). (2017). Cabaran kewangan isi rumah miskin bandar. Ringgit.

Bank Negara Malaysia. (2015). Laporan Tahunan 2015. Kuala Lumpur: Bank Negara Malaysia.

Burton, J. (1990). Conflict : resolution and prevention. New York : St Martin's Press.

Bank Negara Malaysia. (2017). gaji kehidupan wajar: bukan sekadar menampung keperluan asas. Rencana tahunan laporan BNM. Diakses daripada www.bnm.gov.my

Bank Negara Malaysia. (2018). Laporan Tahunan 2017. Kuala Lumpur: Bank Negara Malaysia.

Barreiro, I. C. (2006). Human Development assessment through the Human-Scale Development approach: integrating different perspectives in the contribution to a sustainable human development theory: Thesis Doctoral. Diakses daripada Universitat Politecnica de Catalunya: http://hdl.handle.net/2117/93239

Creek, C. (1959). Consumer decision making and buying behaviour. Proceedings of the Annual Meeting, 32, 80-84.

Duesenberry, J. (1949). Income, saving, and the theory of consumer behavior. Cambridge: Harvard University Press.

Dunn \& Norton. (2014). Prosocial spending and happiness: using money to benefit others pays off. Current Direction in Psychological Science, 23(1), 41-47.

Friedman, M. (1957). The permanent income hyphotesis. In M. Friedman, A Theory of the consumption function (pp. 20-37). New Jersey, U.S.A: Princeton University Press

Husna Sulaiman \& Jariah Masud. (2012). Determinants of income security of older persons in Peninsular Malaysia. Pertanika, Journal of Social Sciences and Humanities, 20(1), 239-250.

Husniyah, A.R., Mohd Fazli, S., Norhasmah, S., Mohd Amim, O., Norhafifah, S., \& Fatin Farwizah, M.R. (2017). Financial practices and physical health influencing financial health of Malaysian employees. Malaysian Journal of Consumer and Family Economics, 20, 1-20.

Institut Kajian Khazanah. (2018). The state of household 2018 : different realities. Kuala Lumpur, Malaysia: Institut Kajian Khazanah. Diakses daripada http://www.krinstitute. org/assets/contentMS/img/template/editor/FullReport_KRI_SOH_2018.pdf

Jabatan Perangkaan Malaysia. (2017). Laporan penyiasatan perbelanjaan isi rumah 2016. Diakses daripada www.dosm.gov.my/v1/index.php? $r=$ column/pdfPrev\&id=V3R4SHB meUhDUW1ETjZUbXdWbXB2dz09

Kamus Dewan. (2010). Edisi keempat. Kuala Lumpur: Dewan Bahasa dan Pustaka. 
Kumpulan Wang Simpanan Pekerja (KWSP). (2019). Belanjawanku : expenditure guide for Malaysian Individuals and Families. Kuala Lumpur: Kumpulan Wang Simpanan Pekerja (KWSP).

Lee, Y.-K., \& Chang, C.T. (2007). Who gives what to charity? Characteristics affecting donation behavior. Social Behavior and Personality, 35(9), 1173-1180

Malaysiakini.(2016, Nov 1).Harga sesetengah minyak masak naik hingga 60\% . (2016). Diakses daripada https://www.malaysiakini.com/news/361306.

Malaysiakini (2017, Oktober 25). Kebanyakan rakyat Malaysia tidak mampu bersara. Diakses daripada http://www.malaysiakini.com.news/399453

Martins, J.M.,Yusuf, F., \& Swanson, D. A. (2012). Consumer demographics and behaviour. Springer. doi:10.1007/978-94-007-1855-5.

Maslow, A. (1943). A theory of human motivation. Psychological Review. 50: 370-396

Max-Neef, M. (1992). Development and human needs. In P. M.-N. Ekins, Real-life economics. understanding wealth creation (pp. 197-213). London: Routledge.

Mohd Taib Osman. (1989). Agama dan kepercayaan orang Melayu : organisasi dan struktur. In M. T. Osman, Masyarakat Melayu, struktur, organisasi dan manifestasi (pp. 146203). Kuala Lumpur: Dewan Bahasa dan Pustaka.

Murallitharan Munisamy, Tharini Thanapalan, Pattaraporn Piwong, Alessio Panza, \& Sathirakorn Pongpanich. (2018). Assessment of the validity and realibility of an urban household health expenditur (HHE) questionnare in Kuala Lumpur. Journal of Health Research, 32(1), 24-35.

Murray, M., Pauw, C., \& Holm, D. (2005). The house as a satisfier for human needs : a framework for analysis, impact measurement and design. World Congress on Housing : Transfoming Housing Environments through Design. Pretoria, South Africa.

Nor Aini Haji Idris, Norlida Hanim Mohd Salleh, \& Mohd Ali Mohd Noor. (2011). Faktor penentu perbelanjaan kesihatan di kalangan golongan bekerja. Persidangan Kebangsan Ekonomi Malaysia ke VI (PERKEM) (pp. 124-130). Bangi: Universiti Kebangsaan Malaysia. Diakses daripada http://www.ukm.my/fep/perkem/pdf/perkemVI/ PERKEM2011-2-4B6.pdf

Nurshuhada Zainon, Faizul Azli Mohd-Rahim, Syazwani Sulaiman, Saipol Bari AbdKarim, \& Atikah Hamzah. (2017). Factors affecting the demand of affordable housing among the middle-income groups in Klang Valley Malaysia. Journal of Design and Built Environment, 1-10.

Rosenberg, M. (1960). A structural theory of attitude dynamics. Public Opinion Quarterly, 24(2), 319-340.

Rusli Latimaha, Zakaria Bahari \& Nor Asmat Ismail. (2018). Factor influencing the basic needs budget among the middle income earners in selected major cities in Malaysia. Journal Ekonomi Malaysia, 52(3), 29-40.

Sabstu, J. (2014). Rising living cost : Impact to the citizen. Dimensi Koop, 15-16. Soc Indic Res, 116(3), 755-770 
Solomon, M. R. (1996). consumer behavior (3 ed.). Englewood Cliffs, New Jersey: Prentice Hall, Inc.

Stockhausen, G. (1998). Leisure in the economic thought of John Paul II. International Journal of Social Economics, 25(11/12), 1672- 1683

Suhaimi Abd Samad \& Norma Mansur. (2013). Population ageing and social protection in Malaysia. Malaysian Journal of Economic Studies, 50(2), 139-156.

Syadiyah Abdul Shukor, Intan Fatimah Anwar, Hisham Sabri, Sumaiyah Abd Aziz, \& Avylin Roziana Mohd Ariffin. (2016). Giving behaviour : who donates cash waqf? Malaysian Journal of Consumer and Family Economics, 19, 87-100.

The Edge.(2019). Economy, cost of living tops rakyat concerns. Diakses daripada www. theedgemarkets.com.

The Star. (2018, August 29). Don: Government needs to plan for ageing Malaysians. Diakses daripada https://www.thestar.com.my/news/nation/2018/08/29/don-govtneeds-to-plan-for-ageing-msians/

Utusan Malaysia (2016, Ogos 1). Hari Raya tingkatkan jualan kenderaan. Diakses daripada http://www.utusan.com.my/bisnes/ekonomi/hari-raya-tingkatkan-jualankenderaan-1.364585

Wan Abdul Kadir Wan Yusof. (2000). Tradisi dan perubahan norma dan nilai di kalangan orang-orang Melayu. Kuala Lumpur, Malaysia: Masfami Enterprise.

Wan Nor Azriyati Wan Abd Aziz, Noor Rosly Hanif \& Kuppusamy Singaravello. (2011). Affordable housing within the middle income households in Malaysia: Challenge to enter homeownership. Australian Journal of Basic and Applied Sciences, 5(8), 258-267.

Tarikh Peroleh (received): 25 Mac 2020

Tarikh Terima (accepted): 29 Disember 2020 